Paired with this commentary authored by Editor, Dr Todd Rosengart, the "News and Views" section features an editorial written by Dr Frazier providing his firsthand experience in a piece titled, "Mechanical Circulatory Assist Device Development at the Texas Heart Institute: A Personal Perspective."

These articles, as well as the Discussion in Cardiothoracic Treatment and Care on "State of the Art: CABG" moderated by Dr John Puskas and paneled by experts Drs Harold Lazar, Michael Mack, Joseph Sabik, and David Taggart, present our readers with perspectives on bilateral ITA grafting, endoscopic conduit harvesting, hybrid procedures, and the future of OPCAB.

New online: The audio recording of the Discussion is available at http://www.semthorcardiovascsurg.com/.

The last highlighted article is a "State of the Art" article by Dr Nagashree Seetharamu from New York University Cancer Center, who discusses promising immunotherapeutic strategies non-small cell lung cancer.

\section{Operative Techniques in Thoracic and Cardiovascular Surgery}

Operative Techniques in Thoracic and Cardiovascular Surgery Editor, Dr J. William Gaynor, would like to call your attention to the next issue's featured articles. We are delighted to introduce the new "Transplant Surgery" section to $O p$ Techs. Dr Duane Davis, the Associate Editor, has invited Drs Carmelo Milano and Jonathan Chen to describe transplant surgeries following pretransplant mechanical circulatory support as a bridge to transplant.

Dr Benjamin Kozower, Associate Editor for the "General Thoracic" section has chosen Dr Rishindra Reddy to provide an excellent description of management of esophageal diverticulum. The vast majority of esophageal diverticula are secondary to motility disorders and his review provides a clear and appropriate strategy for treating them.

Dr Glen Van Arsdell now leads the "Congenital" section and invited Dr Kirk Kanter to share his thoughts on and applications for performing Fontans with an eye to distributing blood flow from the inferior vena cava to both lungs equally by utilizing a $\mathrm{Y}$ graft.

Dr John Kern, Associate Editor for the "Adult Cardiac" section, has invited Drs John Conte and Tom Gleason to describe their preferred methods of repair of anterior and posterior post-infarct VSDs.

\section{The Western Thoracic Surgical Association}

\section{Applications for Membership}

The WTSA is now accepting Applications for Membership online for Active as well as Candidate membership status. Visit the WTSA Web site at www.westernthoracic.org to read the complete membership eligibility requirements and to initiate an online application.

\section{Active Member}

$\$ 325.00$ annually, plus $\$ 50.00$ initiation fee

Applicant must meet all membership criteria, including but not limited to:

- Reside within or have completed a cardiothoracic residency training program within the geographic limits of the Association.

- Have been engaged in the practice of thoracic and cardiovascular surgery for at least three years following completion of postgraduate training. If a candidate completed his/her thoracic surgical residency in an institution within the geographic limits of the Association, such completion may count towards one of the three years of practice.
- Have a full and unrestricted license to practice medicine in his or her respective state or province, and have a current appointment on the surgical staff of a hospital with no reportable action pending which could adversely affect such applicant's staff privileges at any hospital.

\section{Candidate Member}

$\$ 100.00$ annually

Applicant must meet all membership criteria, including but not limited to:

- Be matched or enrolled in either a cardiothoracic surgery education program accredited by the Residency Review Committee for Thoracic Surgery under the authority of the ACGME or a program approved for cardiothoracic surgery education by the Royal College of Surgeons of Canada-or their equivalency-from within the Association's geographic limits. Individuals who have completed their education in one of the above programs and are in the process of acquiring certification in cardiothoracic surgery by either the American Board of Thoracic Surgery or the Royal College of Surgeons of Canada also are eligible to apply for Candidate membership. 
An application must include the following uploads: a photo, a complete curriculum vitae with bibliography, and, for Active applicants, the 3 most significant articles that s/he personally wrote. The application must be completed and submitted online by March 1, 2015, and all support letter(s) (three for Active applicants, one for Candidates) uploaded by that applicant's sponsor(s) by March 31, 2015, in order for the applicant to be considered for election to membership at the 2015 Annual Meeting.

\author{
WTSA 41st Annual Meeting \\ Save the Date! \\ June 24-27, 2015 \\ Fairmont Chateau Whistler \\ Whistler, British Columbia, Canada
}

\section{The AATS Graham Foundation}

\section{In Its 40th Year, the AATS Graham Foundation Announces New Specialty Programs}

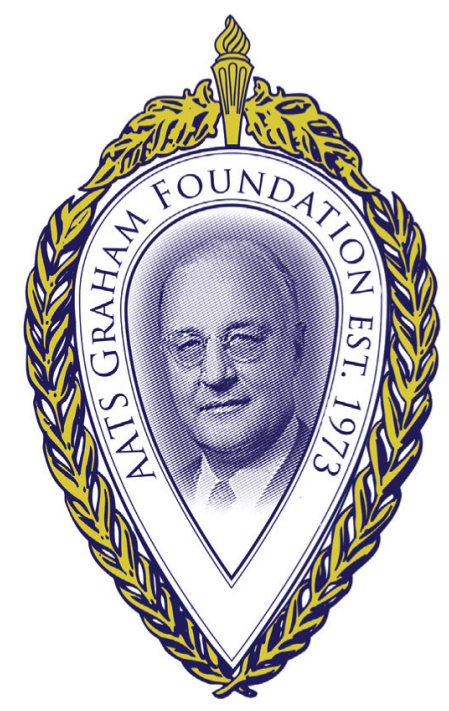

Over the past year, new fellowship programs for medical students, fellows, residents, and international professionals have been developed that provide specialized educational and training opportunities.

\section{The American Board of Thoracic Surgery}

\section{Notices}

The part I (written) examination was held on December 3. It is planned that this examination will be given at multiple sites throughout the United States using an electronic format. The closing date for registration is August 1 each year. Those wishing to be considered for examination must apply online at www.abts.org.

To be admissible for the Part II (oral) examination, a candidate must have successfully completed the Part I (written) examination.

A candidate applying for admission to the certifying examination must fulfill all the requirements of the Board
The Cardiothoracic Surgical Investigator Program caters to cardiothoracic surgeons interested in conducting clinical or translational research, while the Traveling Scholar Program provides young cardiothoracic surgeons from around the world a chance to study clinical techniques at a secondary institution.

Our new Resident Poster Session Scholarship for thoracic surgical residents has become extremely popular and competitive, along with the Critical Care Scholarship program that boasts over 50 students expected to participate in 2014 !

Along with our programmatic growth, we have engaged our Board of Directors to a full complement of eight, complete with two active board committees: Advisory Council headed by Dr Tim Gardner and Development Committee headed by Dr Raphael Bueno.

As our parent Association, the AATS underwrites all operational costs of the Foundation, allowing $100 \%$ of all individuals' contributions to go directly to Foundation programming.

The AATS Graham Research Foundation is driving leadership, learning and innovation in the pursuit of excellence! For more information on the AATS Graham Foundation, please visit http://aatsgrahamfoundation.org.

in force at the time the application is received. Please address all communications to the American Board of Thoracic Surgery, 633 North St Clair Street, Suite 2320, Chicago, IL 60611 (telephone: 312-202-5900).

\section{Requirements for Maintenance of Certification}

Diplomates of the American Board of Thoracic Surgery (ABTS) who plan to participate in the Maintenance of Certification (MOC) process must hold an unrestricted medical license in the locale of their practice and privileges in a hospital accredited by the JCAHO (or other organization recognized by the ABTS). In addition, a valid ABTS certificate is an absolute requirement for entrance into the Maintenance of Certification process. If your certificate has expired, the only pathway for renewal of 